\title{
Comportamento Humano e Recursos Naturais: Qualidade e Disponibilidade da Água Avaliadas pelos Usuários ${ }^{1}$
}

\author{
Ariane Kuhnen ${ }^{2}$ \\ Universidade Federal de Santa Catarina \\ Rafaella Lenoir Improta \\ Universidade Federal do Rio Grande do Norte \\ Scheila Machado da Silveira \\ Universidade de São Paulo
}

\begin{abstract}
RESUMO - A pesquisa buscou conhecer as representações da água em cidades de São Paulo e Santa Catarina. Foram realizadas 296 entrevistas estruturadas com uso de questionário elaborado a partir de eixos temáticos, categorias e variáveis. Para análise dos resultados, realizou-se a exploração textual dos questionários, reconhecendo os núcleos dos discursos e suas características, agrupadas por semelhança de conteúdo. A maioria dos entrevistados indica a água como fundamental para a sobrevivência, sendo suficiente no momento atual, porém temem pela sua indisponibilidade no futuro. Apontam as ações humanas como principal responsável pela situação. Conclui-se que os entrevistados questionam os modos de vida e de produção atual, a organização da sociedade e, por consequência, chamam a atenção para o modo insustentável de consumo de água.
\end{abstract}

Palavras-chave: água; percepção; psicologia ambiental.

\section{Human Behavior and Natural Resources: Quality and Availability of Water as Evaluated by Users}

\begin{abstract}
The research aimed to know the representations of water in some cities in Sao Paulo and Santa Catarina. Two hundred and ninety six structured interviews were conducted using a questionnaire elaborated on themes, categories and variables. In order to analyze the results, textual exploration of the questionnaires was performed identifying the discourse nuclei and their characteristics, grouped by content similarity. The majority of respondents indicated water as fundamental to survival. They also affirmed that it is currently sufficient, but they fear its unavailability in the future. They say that human actions are primarily responsible for this situation. It is concluded that the respondents question the ways of life and production nowadays, society organization and, consequently, they call attention to the unsustainable way of water consumption.
\end{abstract}

Keywords: water; perception; environmental psychology.

A água é um bem extremamente fundamental para a sobrevivência de todo o planeta. Ao longo da história humana, o ser humano sempre necessitou de água. Porém, diferentemente dos outros seres vivos, o ser humano também necessita desse recurso para garantir o desenvolvimento de suas atividades produtivas. Em algumas, muito explicitamente, como, por exemplo, na agricultura; já em outras atividades, como na indústria ou pecuária, a necessidade da água se apresenta um pouco mais implícita (Trigueiro, 2005).

Além disso, a qualidade da água pode ser uma medida que diagnostique o estado de conservação do ambiente como um todo, já que por meio de sua análise se verifica o grau de erosão do solo, os lançamentos orgânicos, a poluição por

1 Apoio financeiro: Ministério da Saúde - FUNASA. Colegas colaboradores: Pedro Roberto Jacobi, Roberto Moraes Cruz, Fernanda G. Müller, Guilherme Baldo e Maisa M. Hortal. Origem do Trabalho: Pesquisa realizada para o Ministério da Saúde - FUNASA - Programa de Pesquisa em Saúde e Saneamento, sob o título Representações e Práticas Sociais Ligadas à Água - REÁGUA.

2 Endereço para correspondência: Universidade Federal de Santa Catarina, Departamento de Psicologia, Laboratório de Psicologia Ambiental. Florianópolis, SC. CEP 88040-970. Fone: (48) 3721-8574; Fax: (48) 3721-9283.E-mail: ariane@cfh.ufsc.br. esgotos e, inclusive, a poluição atmosférica. Não por outra razão, as bacias hidrográficas são atualmente utilizadas como unidades de planejamento de gestão ambiental (Freitas, 2000; Graff, 2000).

Ocorre que o comportamento humano é considerado a maior causa de deterioração ambiental. A utilização desregrada do meio ambiente como recurso ao longo dos séculos, agravada com o crescimento populacional, semeou e deu frutos à crise ambiental contemporânea, que não é uma crise do ambiente e sim uma crise das pessoas-nos-ambientes (Clark, 1995, Oskamp, 2000; Pinheiro, 1997; Pol, 1993; Stern, 2000). Além disso, a superpopulação humana exige cada vez mais recursos para sua sobrevivência (Corral-Verdugo, 2001). Incluído nesse panorama está o uso insustentável do recurso água nas atividades humanas, comprometendo sua qualidade e preocupando por sua iminente escassez (Corral-Vedugo, 2001; Oskamp, 2000; Trigueiro, 2005). Por esse fato, o tema da relação com a água é bastante presente atualmente na sociedade, tanto na comunidade acadêmica quanto nos demais segmentos. As questões buscadas e tratadas pelas Ciências Humanas agrupam-se em torno de temas como o papel das percepções, representações, das dimensões individuais e socioculturais e das práticas cotidianas em torno do tema da 
água. Alguns estudos vêm sendo realizados buscando compreender esses fenômenos. Dentro desse escopo encontra-se esta pesquisa.

Segundo Corral-Verdugo, Armenta, Urías, Cabrera e Gallego (2002) e Vargas e Paula (2002), as atitudes, informações e expectativas dos usuários da água são fundamentais para garantir uma gestão sustentável dos recursos hídricos. Sendo assim, para que se possa envolver os usuários no processo de gestão dos recursos hídricos é necessário entender a maneira como percebem e interagem com o ambiente. Segundo Corral-Verdugo (2001, 2002, 2003), as motivações para economia estão entre os preditores psicológicos de conservação de água significativos de ações pró-ambientais. Essas motivações podem ser agrupadas em três instâncias: a água é economizada para cooperar com alguma campanha de conservação; para pagar menos pelo recurso; ou ainda, devido à punição pelo consumo excessivo. Cabrera, Gallego e Lomeli (2002) e Corral-Verdugo (2002) apontam variáveis demográficas e contextuais que influenciam na economia de água, tais como sexo, lugar de origem, escolaridade, renda e conhecimento ambiental.

No que diz respeito à percepção ambiental do recurso água, Vargas e Paula (2003) concluem que apesar de existirem estudos objetivando conhecer a percepção da água, em geral tais estudos focam aspetos fragmentados da relação que temos com o recurso água. Buscando dar amplitude à temática, esses autores verificaram que a percepção da água é marcada pela falta de conhecimentos acerca de mananciais de abastecimento, do tratamento, da legislação e mesmo do consumo familiar e do custo da água.

Ribeiro e Galizzoni (2003) investigaram os usos locais da água para compreender de que forma tais usos dialogam ou conflitam com as leis e técnicas propostas pelas agências reguladoras do recurso. Em suas conclusões, referem que qualidade e sensibilidade estão associadas também à captação. A boa água, ou água fina é conseguida em brotos, olhos d'água, nascentes preservadas, com mato em volta, ou surge sobre pedras, possuindo sentido daquilo que é puro e intocado, nascido da terra. Dessa forma, as distintas hierarquias de usos das águas estão relacionadas à disponibilidade de fontes e de sua qualidade: existe água para beber, para consumo animal, para lavar roupa e regar. Vale dizer que há uma percepção de escassez que pode ser, ao mesmo tempo, qualitativa e quantitativa. Qualidade aí faz relação com classificações culturais, captação e partilha; por isso o importante é zelar prioritariamente pelas pequenas águas, não as grandes; estas últimas estão fora do entendimento que a população costuma conceber para a ação humana. Mesmo na escassez, há resistência à idéia de armazenar água. Inclusive, o acesso à água corrente e nascente está associado à própria ideia de um direito natural de todos.

O que esses e outros estudos parecem advertir é que face à amplitude dos problemas relacionados á água, a preocupação maior da época contemporânea parece ser a questão da natureza dentro da esfera interrogativa sobre a relação construída entre os seres humanos e o ambiente. A preocupação com a água talvez seja um dos símbolos mais prementes de uma mutação necessária na relação do ser humano com esse recurso. A gestão dos recursos hídricos tem sido identificada como a questão de maior poder integrador entre as questões ambientais e a sociedade. O ano de 2005 marcou o início da Década Internacional da Água para a Vida, que visa reduzir pela metade, até 2015, o número de pessoas sem acesso à água potável e ao saneamento básico, e acabar com a exploração insustentável dos recursos hídricos.

Mas, infelizmente, o distanciamento entre ciência, tecnologia e políticas públicas faz com que as atitudes e os comportamentos da população venham sendo avaliados pelas autoridades e serviços públicos a partir de estereótipos que consideram as reações individuais relativas ao uso da água como indiferença, ignorância e desperdício, embora o olhar devesse combinar estratégias político-tecnológicas e sócio-comportamentais. A base desta pesquisa ancora-se no postulado de que, para intervir no segundo plano, devem ser identificados os determinantes dos comportamentos que se quer manter ou modificar em relação aos recursos naturais (Corral-Verdugo, 2003). Portanto, organizou-se o estudo em torno do objetivo de investigar processos subjacentes aos conhecimentos e comportamentos relativos ao abastecimento de água, buscando trazer à tona as representações sociais de seus usuários.

Sendo assim, este estudo aponta para uma dimensão onde se inscrevem junto às representações outros fenômenos psicológicos, como: crenças (conceitos), motivos (valores), atitudes (avaliação), habilidades (ação) e normas (ética). Esse conjunto de fenômenos culmina, então, por promover representações sociais muitas vezes paradoxais, ora ambientalmente antropocêntricas, ora ecológicas e relevantes para que se inscrevam novos modelos de relação entre a humanidade e o ambiente. Esse encontro de novas e velhas idéias num movimento dialético é próprio do fenômeno humano chamado por Moscovici $(1981,1989)$ de Representação Social. Enquanto imagens, opiniões e atitudes somente traduzem a posição e a escala de valores de uma informação circulante na sociedade, representações ainda produzem comportamentos e se relacionam com o meio. É um conhecimento espontâneo, do senso comum e que orienta a comunicação, servindo de interação com o mundo e com os outros. O conceito de representação social pressupõe que o próprio processo de representação constrói o objeto de representação, ou seja, é produto e processo. Portanto, vale lembrar que meio ambiente, por se tratar de um tema complexo, apresenta-se em representações não regidas pelo princípio da não-contradição (Castro, 2003). Um dos desafios talvez seja, entendendo como se dá esse processo, intervir conciliando e articulando ideias que estão mais perto ou mais longe dos ideais ecológicos.

\section{Método}

\section{Participantes}

O critério de escolha dos participantes foi essencialmente serem usuários dos serviços de abastecimento de água. Para definir o tamanho da amostra, optou-se pelo critério psicométrico usado para escalas de atitude, o qual busca identificar o número de respondentes necessários para gerar um grau de saturação do fenômeno ou característica medida, 
ou seja, quando os dados capturados pelo instrumento de pesquisa começam a se repetir ou reduzir significativamente sua variabilidade. $\mathrm{O}$ processo de saturação se inicia quando a quantidade de itens de um questionário é multiplicada por uma escala que varia de seis (mínimo) a 10 (ótimo) (Pasquali, 1999). Para esta pesquisa, utilizou-se o critério mínimo de seis, multiplicado pela quantidade de itens (47), prevendo a necessidade de aplicar 282 questionários para se alcançar o objetivo proposto. Entretanto, foram entrevistados 296 usuários.

\section{Instrumento}

O presente estudo utilizou como principal instrumento a entrevista estruturada. Para sua construção, algumas etapas foram seguidas. A primeira se dedicou à definição do construto, ou seja, à formulação teórica que definiu e explicou as características e a natureza do fenômeno psicológico a ser pesquisado - representação da água.

A segunda etapa foi de elaboração do questionário. Este foi composto por perguntas abertas e fechadas. Realizou-se o processo de definição constitutiva com a elaboração de categorias, que foram definidas e valoradas. Um passo relevante na fase de criação das categorias foi o processo de definição. Atribuiu-se significado e valor de uso a cada categoria, facilitando, dessa forma, a observação de seus atributos, o que culminou na formulação das questões (itens) que tinham como objetivo capturar a magnitude de suas variáveis para as diferentes categorias pré-estabelecidas.

Em seguida, definiram-se as variáveis mais importantes ou mais significativas que representavam a dimensão de cada uma das categorias. Nesse processo, observou-se o campo semântico em estudos semelhantes e foram consultados profissionais da área de meio ambiente. A Tabela 1 apresenta as categorias e as variáveis correspondentes.
O questionário final foi criado a partir da decomposição das propriedades do construto a fim de garantir que as perguntas realizadas se enquadrassem nas categorias. Com os itens do instrumento definidos e alocados, foi realizada inicialmente a análise semântica, que teve como objetivo verificar se todos os itens eram compreensíveis para uma amostra dos membros da população à qual o instrumento se destinava. Buscou-se, então, encontrar a melhor forma de perguntar, a melhor proposição para as finalidades de quem iria responder.

Partiu-se para a terceira etapa - a análise de conteúdo. Almejou-se confrontar as hipóteses contidas no construto com a opinião de juízes (experts: três especialistas, dois que possuíam experiência na elaboração de questionários e um com experiência no assunto em estudo). Mantiveram-se os itens com $80 \%$ de concordância no questionário piloto. Quando o percentual de concordância ficou entre 60\% e 80\%, o item foi modificado, sendo os itens com menos de $60 \%$ de concordância desprezados.

A quarta etapa do processo de avaliação do instrumento foi a aplicação piloto do questionário em uma cidade localizada na região metropolitana de Florianópolis. A escolha dessa cidade garantiu diversidade dos participantes da população que seria trabalhada. A validade empírica teve como finalidade verificar se a medida, agora em forma de questionário, era comunicável e pertencente ao grupo semântico da população. Após a aplicação do piloto foram realizados ajustes ao questionário, alterando ou retirando itens que se mostraram confusos ou incompreensíveis para os entrevistados.

\section{Escolha das cidades}

Os critérios para a escolha das cidades seguiram, primeiramente, a orientação do órgão financiador da pesquisa. Além disso, buscou-se contemplar contextos sociais distintos

Tabela 1. Categorias e variáveis utilizadas na elaboração do questionário.

\begin{tabular}{|c|c|c|}
\hline Categorias & \multicolumn{2}{|c|}{ Variáveis } \\
\hline \multirow{3}{*}{$\begin{array}{l}\text { Simbologia da água: expressa meios para avaliar o significado ou a } \\
\text { importância do recurso água para o indivíduo no âmbito doméstico } \\
\text { e societal. }\end{array}$} & Significado da água & \\
\hline & Importância da água & $\begin{array}{l}\text { Geral } \\
\text { Para saúde das } \\
\text { pessoas }\end{array}$ \\
\hline & & Para vida no planeta \\
\hline
\end{tabular}

Quantidade

Percepção da disponibilidade da água: expressa como o indivíduo discrimina a quantidade, as fontes e recursos por meio dos quais a água está disponível em âmbito doméstico e societal.
Fontes disponíveis

Pessoal

Social

Consciência em relação ao futuro da disponibilidade da água 
(rural e urbano), restringindo-se às cidades beneficiadas por sistemas de abastecimento de água por rede, que faziam parte de comitês de bacias hidrográficas, e que tinham reconhecimento de atuação da sociedade civil e científica com projetos ambientais (ONGs, outros projetos de pesquisa e extensão universitários etc.). Além disso, essas cidades deveriam estar situadas geograficamente de tal forma que apresentassem condição logística para a pesquisa. Dessa forma, as cidades escolhidas no estado de Santa Catarina foram: Santa Rosa de Lima, Santo Amaro da Imperatriz, Rancho Queimado, Balneário Camboriú e Joinville. Já no estado de São Paulo, as cidades escolhidas foram: São Paulo (bairro do Butantã), Embu das Artes e Taboão da Serra. A escolha de cidades em diferentes contextos populacionais e regionais permitiu que fossem comparadas realidades diversas.

\section{Procedimento}

Os participantes foram entrevistados em suas residências ou em vias públicas, como praças ou no comércio. Adotouse a estratégia de conduzir a entrevista com uma dupla de pesquisadores, sendo um destes responsável pelos questionamentos e o outro pelas anotações no instrumento.

\section{Análise de dados}

O trabalho de análise dos dados iniciou pela exploração textual dos questionários, em que se buscou delinear os temas presentes no texto, reconhecendo os núcleos dos discursos, bem como suas principais características. As respostas obtidas com base nas entrevistas definiram o campo semântico do estudo. Posteriormente, essas respostas foram analisadas e agrupadas por semelhança de conteúdo. Após a definição das diferentes características observadas para cada questão, os dados passaram por tratamento estatístico através do Programa SPSS (Statistical Package for the Social Sciences). Com o referido software, foram feitas análises descritivas, bem como cruzamentos entre dados de cada estado, grupos de cidades e as diferentes características observadas na amostra para cada questão.

\section{Resultados}

Para a análise dos dados, inicialmente, as respostas foram agrupadas em termos de características sócio-demográficas. Em seguida, foram analisados os dados referentes às representações do recurso água.

\section{Dados sócio-demográficos}

A amostra da pesquisa foi constituída de 296 respondentes, sendo 44,7\% homens e 55,3\% mulheres. Mais da metade dos participantes era casada $(55,3 \%)$ e $36,9 \%$ estava acima de 45 anos. Os anos de escolaridade variaram entre 8 e 14 anos. A maioria trabalhava em atividades do setor privado, com renda variando entre 3 a 10 salários mínimos alcançados pelo casal $(39,7 \%)$, e possuía residência própria. Somente $13,2 \%$ da amostra morava há menos de 5 anos no local.

\section{As representações do recurso água}

Os demais itens do questionário foram tratados optandose inicialmente por agrupar as cidades por macrotendência, ou seja, o comportamento da amostra total e da amostra por estado. Em seguida, uma segunda análise foi executada, chamada de microtendência, onde optou-se por agrupar as cidades em metrópoles, semi-urbanizadas e rurais. Esses agrupamentos seguiram a tendência de considerar metrópole o conjunto de cidades que exercem influência funcional, econômica e social sobre as cidades menores. São consideradas como cidades semi-urbanas aquelas localizadas próximas a uma metrópole, muitas vezes servindo como cidadesdormitório, em que a atividade econômica está geralmente baseada no comércio e na prestação de serviços. Já as cidades localizadas em região rural se caracterizam por terem na agropecuária a principal atividade econômica, grande parte de seus moradores residirem fora do perímetro urbano e apresentarem baixa densidade populacional.

No que diz respeito à categoria simbologia da água, de modo geral a água, enquanto recurso, foi percebida pela amostra como um tema essencial para o presente e o futuro, tanto no âmbito doméstico quanto societal. Tal representação está sedimentada em noções valorativas e de direitos. Para a amostra geral, a água simbolicamente foi definida a partir da avaliação do significado dado tanto no nível local quanto global. $\mathrm{O}$ mais importante significado dado à água se liga a temas relativos à 'sobrevivência' (49\% da amostra), definida pela importância dada à água como necessária, essencial e fundamental para a qualidade de vida. Também nessa categoria surgem como relevantes as atividades relativas ao 'cotidiano' (32\% da amostra), como utilização do recurso em tarefas diárias de limpeza, alimentação, entre outras. Comparando o significado da água com os dados demográficos, homens e mulheres, jovens e adultos, na mesma proporção, percebem a água como ligada à manutenção da sobrevivência - ou seja, as variáveis demográficas não exercem significativa influência.

Observando-se os dados da Tabela $2^{3}$, decompostos por microtendência (desde as cidades mais urbanizadas até as rurais), vê-se maior incidência de valoração do modo de vida cotidiana como dependente do uso da água assim como o recurso é indicado como essencial à sobrevivência. Essas são as duas categorias (cotidiano e sobrevivência) que se sobressaem, indistintamente, em relação às outras, nas três regiões. Para os moradores da região metropolitana essas duas categorias apresentaram pesos semelhantes (42\% para sobrevivência e $46 \%$ para cotidiano), o mesmo não ocorrendo para os moradores das regiões semi-urbanas e rurais. Para esses dois últimos grupos de moradores, chama atenção que a sobrevivência ligada ao recurso água é mais fortemente

3 A soma percentual aqui e em outras tabelas subsequentes excede $100 \%$ já que certas perguntas do questionário possibilitavam resposta múltipla e alguns respondentes citavam mais de uma alternativa. Dessa forma, o discurso dos respondentes foi classificado em mais de uma unidade de análise na categorização do discurso. 
Tabela 2. Porcentagem de respostas da amostra por grupo de cidades na categoria analítica Simbologia da água.

\begin{tabular}{lccc}
\hline \multirow{2}{*}{ Respostas } & \multicolumn{3}{c}{ Região } \\
\cline { 2 - 4 } & Metropolitana & Semi-urbana & Rural \\
\hline Finitude & 3 & 10 & 5 \\
Boa qualidade & 9 & 10 & 10 \\
Má qualidade & 4 & 4 & 5 \\
Natureza & 10 & 12 & 5 \\
Sobrevivência & 42 & 50 & 65 \\
Cotidiano & 46 & 24 & 22.5 \\
\hline
\end{tabular}

marcada em contraposição à importância da água para as atividades cotidianas (50\% e $24 \%$, respectivamente, para os moradores das regiões semi-urbanas; $65 \%$ e $22,5 \%$, respectivamente, para os moradores das regiões rurais).

Comparando esses dados com os da amostra toda (macrotendência), conclui-se que tal detalhamento (por microtendência) oportunizou o entendimento de que a representação da água apresenta nuances consideráveis por região. Pode-se inferir que os moradores das regiões menos urbanizadas estejam mais sensibilizados que os da região mais urbanizada quanto à vinculação do recurso água à sobrevivência.

Nos parece que a água associada ao conforto cotidiano, seja pela disponibilidade do serviço de abastecimento (infraestrutura técnica de redes e estações de tratamento) e/ou pelas possibilidades de lazer (parques aquáticos, piscinas), assim como recurso vital e patrimonial comum, suscita um caráter ambíguo, já que associa benefícios (uso) e preservação (economia).

A dimensão avaliativa e normativa da água pode ser sentida em trechos destacados do discurso dos usuários ao responderem à questão: $O$ que lhe vêm à cabeça ao se falar em água? Os entrevistados afirmaram: "Quando acordo eu agradeço por ela existir"; "Sem água, o que seria de nós?"; "A maior riqueza do mundo é a água”; "Saúde, vida, sem água não nasce nada”; e "Água significa tudo, sobrevivência, vida”.

A segunda categoria analisada refere-se à percepção da disponibilidade da água que recebem em sua casa, em termos de discriminação da quantidade, assim como das fontes e recursos por meio do qual a água está disponível em âmbito doméstico e societal. Do total da amostra [Santa Catarina (SC) e São Paulo (SP) juntos], 89\% responderam afirmativamente quanto à suficiência. A análise por macrotendência mostra que entre os paulistas, 98\% consideram suficiente a água que chega em suas casas, enquanto $81 \%$ dos catarinenses assim percebem a suficiência do recurso. Em SC, 19\% dos entrevistados não concordam que seja suficiente e em SP, 2\%. Esses dados demonstram uma avaliação distinta entre os estados quanto à discriminação de suficiência da água que recebem em suas residências, sendo os paulistas os mais satisfeitos. Os dados por microtendência, sobre a afirmação de ser suficiente a água que chega em suas casas, são os seguintes: região rural 98\%, semi-urbana 82\% e metrópole $95 \%$.
Já em termos de disponibilidade do recurso no futuro, $77 \%$ da amostra total demonstra descrédito no futuro, ou seja, são pessimistas, crêem que não haverá água suficiente. No entanto, $23 \%$ da amostra é otimista em relação ao futuro, apostando que o recurso não faltará.

A partir desse resultado, "pessimistas" e "otimistas" foram distribuídos de forma mais detalhada, buscando entender como cada uma das tipologias vinculava a percepção do suprimento de água ao próprio recurso ou ao comportamento humano. Dessa forma, entendeu-se por pessimista em relação ao recurso, os usuários que percebiam a escassez ou sua diminuição ao longo do tempo. Na fala de um dos entrevistados é possível identificar o padrão de tal discurso: "A água vai acabar, pois o planeta vem sofrendo com as catástrofes naturais, mudanças climáticas". Já entre os pessimistas em relação ao comportamento estão os sujeitos que responsabilizam as ações humanas pela escassez. Alegam que o desperdício, o descaso com a natureza, a superpopulação, a falta de educação e de fiscalização são os principais itens indicativos de problemas comportamentais que acarretam em fragilidade e escassez do recurso. Esse grupo apresenta discursos nos quais alegam: "Têm que cuidar mais, se tivessem cuidado da água essa seria pura, seria tudo diferente”.

No grupo dos otimistas em relação ao recurso estão os usuários que percebem abundância do recurso, atestado por afirmações como: "Pode diminuir, mas não vai acabar". Os otimistas em relação ao comportamento o percebem como responsável pela conservação da água. Nesse grupo há uma crença nas possibilidades educativas e tecnológicas para superar ou melhorar a situação. $\mathrm{O}$ discurso recorrente é o de que a educação pode diminuir problemas futuros relativos à água: "O pessoal cuida da nascente, porque se desmatar prejudica. São conscientizados"; "Se as pessoas mudarem a atitude delas..., acho que sim, porque afinal quem vai querer consumir água suja, tóxica?".

Finalmente, os dados se apresentam dessa forma: dentre os entrevistados, são pessimistas em relação ao recurso, $37,8 \%$ do grupo, e pessimistas em relação ao comportamento, $71,6 \%{ }^{4}$. São otimistas em relação ao recurso, $35,8 \%$; já são otimistas em relação ao comportamento, 53,7\% desse grupo $^{5}$.

Como se pode observar nas tabelas 3 e 4, mantém-se na análise por microtêndencia a avaliação pessimista em relação à disponibilidade do recurso no futuro, e tanto pessimistas quanto otimistas das três regiões (metropolitana, semi-urbana e rural) ancoram no comportamento humano a percepção da causa da insustentabilidade do recurso. $\mathrm{Na}$ área semi-urbana, $68,1 \%$, na metropolitana, $71,8 \%$ e na região rural, $88 \%$ dos entrevistados são pessimistas em relação ao comportamento. E os otimistas em relação ao comportamento estão assim distribuídos: $33 \%$ na região semi-urbana, 56,3\% na região metropolitana e 73,3\% na região rural.

Essa argumentação vai ao encontro de resultados de estudos em psicologia ambiental (Pinheiro, 1997; Oskamp, 2000;

4 Os dados totalizam mais de $100 \%$ em função de respostas que atribuem argumentos pessimistas para recurso e também para comportamento.

5 Os dados não totalizam $100 \%$ porque alguns usuários responderam que haveria disponibilidade do recurso no futuro, entretanto não argumentam sua visão. 
Tabela 3. Porcentagem de respostas da amostra por grupo de cidades, na categoria analítica Percepção da disponibilidade da água (pessimistas)

\begin{tabular}{lccc}
\hline & \multicolumn{3}{c}{ Região. } \\
\cline { 2 - 4 } & Metropolitana & Semi-urbana & Rural \\
\hline $\begin{array}{l}\text { Pessimista em relação } \\
\text { ao recurso }\end{array}$ & 38.5 & 39.5 & 28 \\
$\begin{array}{l}\text { Pessimista em relação } \\
\text { ao comportamento }\end{array}$ & 71.8 & & \\
\hline
\end{tabular}

Pol, 1993). Esses autores chegaram a conclusão de que a crise ambiental contemporânea se deve ao uso desregrado dos recursos naturais, estruturando não uma crise do ambiente, mas sim uma crise das pessoas nos ambientes. Observa-se, em algumas falas dos entrevistados, essas constatações: " $A$ minha geração só estragou a água. A minha filha não terá mais água potável" (pessimista quanto à suficiência de água no futuro); "Porque o povo brasileiro está se conscientizando, tem mais economia" (otimista com o futuro). Mas a dúvida cede, dando lugar para a crença na tecnologia, para esse otimista: "Não sei, devido à evolução pode até não faltar porque a tecnologia pode dar conta disso".

\section{Discussão}

A partir dos dados pode-se constatar que o discurso dos usuários está baseado numa construção subjetiva complexa da água. As representações evidenciadas foram construídas em função de dimensões temporais e espaciais, ligadas à experiência pessoal. A categorização do discurso aponta para elementos demonstrativos de que as representações asseguram a organização e estruturação do real, compondo as representações sociais da água.

A sobrevivência aparece com o status de uma representação que se evidencia entre as demais e, afirmando-se como uma representação circulante, a manutenção da sobrevivência implica numa reconsideração notável nas práticas. Ao mesmo tempo, por considerar a água não apenas como recurso, mas como meio de vida, os resultados sugerem aos gestores o anseio da população de ver equacionado o frágil equilíbrio entre as exigências econômicas e a preservação ambiental. Infere-se que a inter-relação de diferentes elementos, que não podem ser pensados separadamente, pode permitir ao gestor avaliar o peso de suas decisões em função desse tipo de percepção da sociedade.

Ao analisar os resultados desta pesquisa em termos do pessimismo e otimismo dos usuários em relação ao recurso água, nos chama a atenção a adequação das tecnologias à vida social. Como afirmam Clark (1995) e Howard (2000), a crença "cega" na tecnologia para resolver os problemas provenientes das atividades humanas é uma séria questão a ser discutidada, haja visto que há um limite para as soluções tecnológicas; essas também, em certos casos, "mascaram" o problema e, muitas vezes, são a própria causa dos problemas humano-ambientais.

Ao observar a forte ênfase que esses entrevistados dirigem aos comportamentos humanos, é importante lembrar o que
Tabela 4. Porcentagem de respostas da amostra por grupo de cidades, na categoria analítica Percepção da disponibilidade da água (otimistas) ${ }^{1}$.

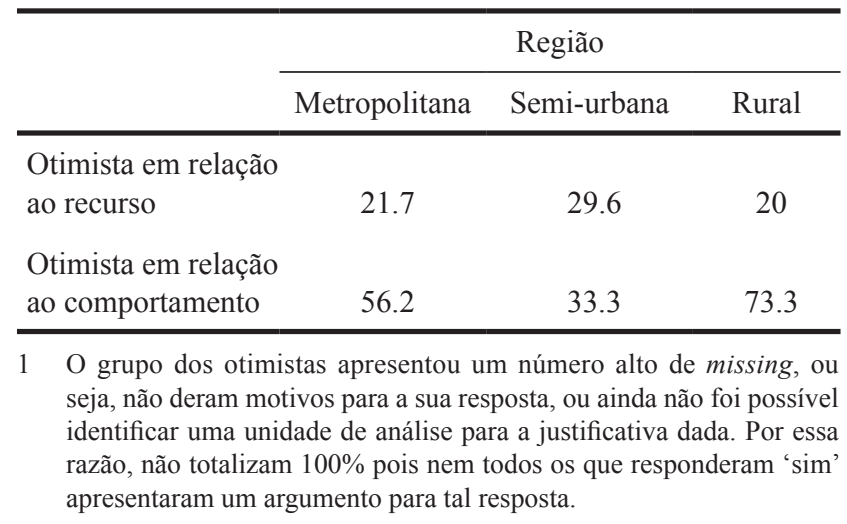

diz Corral-Verdugo (2001); para ele, a educação ambiental pode ser um veículo para o desenvolvimento de competências pró-ambientais, a partir do desenvolvimento dos pré-determinantes para a ação ambiental, tais como atitudes, valores, normas e crenças ecológicas. Aliando habilidades, teremos boas chances de resolução de problemas ambientais pela via da instauração de comportamentos pró-ambientais. Com o desenvolvimento de competências pró-ambientais, têm-se soluções complexas e versáteis para a resolução de problemas, quebrando o sistema normativo que a sociedade estabelece para regular o comportamento de todos os integrantes na sua relação com o contexto sócio-físico. A partir do momento que a pessoa se dá conta dos "mitos ambientais irresponsáveis", ela desenvolve um pensamento ambiental crítico, que lhe permite tomar decisões responsáveis quanto aos problemas.

As representações sociais dependem das características dos indivíduos, de sua experiência, pertencimento e horizonte cultural; como também, implicam estruturas perceptivas, cognitivas, de crenças e saberes. A dimensão de fundo dos resultados apresentados neste artigo está atrelada à condição de informar o papel dessas representações, além de incentivar e instigar práticas que contribuam para se chegar a confluências entre as necessidades humanas e a qualidade ambiental. O percurso desta pesquisa encontra amplamente justificativas para isso. O tema da água é percebido, pela maioria da amostra, como um forte condicionante para o presente e o futuro. Isso demonstra que os entrevistados questionam os modos de vida e os modos de produção atual, a organização da sociedade e, por consequência, o consumo de água, mesmo que o imediatismo da sociedade contemporânea, muitas vezes, conduza a uma percepção de futuro como algo muito distante, provocando uma frágil ligação entre ações presentes e consequências futuras. Além disso, não há nitidez a respeito dos problemas ambientais originados do modo de vida ocidental, que são agravados devido à grande extensão temporal entre a ação humana e seus efeitos deletérios no ambiente (Pinheiro, 2002). Com isso, perpetuam-se valores e crenças descontextualizados dos problemas ambientais ocasionados por esse modo de vida (Clark, 1995). Especificamente sobre o recurso água, Corral-Verdugo (2002) indica que o problema da escassez de água possui componentes psicológicos 
e sociais. As pessoas desperdiçam água influenciadas por motivos, crenças, percepções e normas pessoais. E, ainda, o autor prescreve que são necessários estudos desses componentes para se entender quais características pessoais e situacionais do comportamento podem ser estudadas quando se prevê a promoção do que chama de padrões de consumo responsável de água.

Tais constatações podem ser importantes para que os gestores reconsiderem a forma com que vêm atuando, e, assim, dirijam suas ações para buscar equilíbrio entre as exigências econômicas e a preservação ambiental e envolver a população nas políticas de gestão.

\section{Considerações Finais}

A inclusão das questões ambientais no âmbito das temáticas próprias das Ciências Humanas em geral e da Psicologia em particular, tem avançado nos últimos anos. Entretanto, observou-se ao longo deste trabalho a quase inexistência de aportes teóricos e metodológicos, tanto para definição do construto, como para auxiliar na análise dos dados coletados. Poucos foram os trabalhos alcançados por cuidadosa pesquisa bibliográfica para subsidiar a construção do método, assim como para referenciar, comparar e discutir os dados alcançados por este estudo.

Viu-se a importância de ampliar o escopo dos temas de estudos da ciência psicológica para questões relativas à relação pessoa-ambiente, seja referente à água, como neste caso, ou ao saneamento, poluição atmosférica, mudanças climáticas, preservação da fauna e flora, biodiversidade, áreas de preservação, entre tantos outros temas. A saída possível tem se revelado, a cada dia, pelo caminho do entendimento da interdependência entre as escalas pessoal, social, local e planetária para compreender as realidades presentes e agir mais adequadamente. Como este, estudos dessa natureza podem subsidiar ações na área ambiental. Urge essa tarefa à Psicologia.

Indica-se este tipo de estudo para referendar políticas de gestão e educação ambiental. Os dados oferecem subsídios para colaborar com setores atuantes na área de tratamento de água e saúde pública, assim como auxiliar programas de educação ambiental, e também na identificação de elementos de participação social (políticas públicas). Os resultados podem vir a colaborar no desenvolvimento de uma medida ou ferramenta gerencial para avaliação permanente e comparada sobre as necessidades e comportamentos de consumo da água na população. Sendo assim, observa-se e justifica-se a necessidade de se fomentar estudos que possam conhecer comportamentos adotados frente a problemas ambientais atuais em função das representações do meio ambiente ou algum componente, como a água.

A valorização patrimonial e a aproximação com os espaços da vida cotidiana lançam o ideal de valorização social da natureza. Por exemplo, o estudo da relação que estabelecemos com a água tem se mostrado particularmente fecundo para aspectos relacionados aos recursos hídricos, assim como serve de ressonância para outros aspectos da relação sociedade/natureza. As duas dinâmicas aí presentes, simbólicas e materiais, não são regularmente tratadas como fazendo parte uma da outra. Justapostas, sem comunicação, pouco oferecem a sociedade de maneira geral.

O compromisso dos setores da sociedade comprometidos com o bem estar e a qualidade de vida das pessoas depende, em grande parte, do comportamento humano. O esforço de aproximação das áreas tecnológicas, científicas e de outros campos do saber com certeza tem demonstrado ser o caminho mais promissor para se alcançar algo nesse sentido. As Ciências Humanas podem contribuir com seus aportes de análise. Entretanto, essas análises precisam ser operacionalizadas pelos gestores. Ao mesmo tempo, não se deve cair na falácia de que é possível modelizar a sociedade, acreditar em receitas milagrosas de normas a aplicar para garantir comportamentos almejados. Compreender como as pessoas, em função de sua experiência, seus valores, suas metas e interesses, constroem relações diferenciadas entre si e com o mundo material, oferece um quadro explicativo de suas ações e pode permitir aos sistemas de gestão avaliar o peso de suas decisões.

Ancorado nessa perspectiva, reitera-se a intenção de buscar interlocutores por meio da publicação destes dados. Tal oportunidade pode ser o início de uma rica troca entre pesquisadores e interessados em estudos de questões ambientais.

\section{Referências}

Cabrera, V. O., Gallego, N. B. E., \& Lomelí, D. G. (2002). Relación entre variables demográficas, variables contextuales, conocimiento ambiental y el ahorro de água. Em V. Corral-Verdugo (Org.), Conductas protectoras del ambiente: teoría, investigación y estrategias de intervención (pp. 99-115). México: CONACYT/ $\mathrm{Rm} /$ UniSon.

Castro, P. (2003). Pensar a natureza e o ambiente - alguns contributos a partir da Teoria das Representações Sociais. Estudos de Psicologia, 8, 263-272.

Clark, M. E. (1995). Changes in Euro-American values needed for sustainability. Journal of Social Issues, 51, 63-82.

Corral-Verdugo, V. (2001). Comportamiento proambiental: una introducción al estudio de las conductas protectoras del ambiente. Santa Cruz de Tenerife: Resma.

Corral-Verdugo, V. (2002). Structural model of pro-environmental competency. Environment \& Behavior, 34, 531-549.

Corral-Verdugo, V. (2003). Determinantes psicológicos e situacionais do comportamento de conservação de água: um modelo estrutural. Estudos de Psicologia, 8, 245-252.

Corral-Verdugo, V., Armenta, M. F., Urías, F. P., Cabrera, V. O., \& Gallego, N. E. (2002). Consumo doméstico de la agua, motivación para ahorrala, y la continua tragedia de los comunes. Em V. Corral-Verdugo (Org.), Conductas protectoras del ambiente: teoria, investigación y estratégias de intervención (pp. 81-97). México: CONACYT/Rm/UniSon.

Freitas, W. P. (2000). Águas: aspectos jurídicos e ambientais. Curitiba: Juruá.

Graff, A. C. B. (2000). A tutela dos estados sobre as águas. Em W. P. Freitas (Org.), Águas: aspectos jurídicos e ambientais (pp. 51-75). Curitiba: Juruá.

Howard, G. S. (2000). Adapting human lifestyles for the 21st Century. American Psychologist, 55, 509-515. 
Moscovici, S. (1981). Collective cognition: On social representations. Em J. P. Forgas (Org.), Social cognition: Perspectives on everyday understanding, Vol 26. (pp. 181-209). Londres : Academic Press.

Moscovici, S. (1989). Des represéntations collectives aux representations sociales . Em D. Jodelet (Org.), Les représentations sociales: élements pour une histoire (pp. 62-86). Paris: PUF.

Oskamp, S. (2000). A sustainable future for humanity? How can psychology help? American Psychologist, 55, 406-508.

Pasquali, L. (1999). Instrumentos psicológicos: Manual prático de elaboração. Brasília: IBAPP.

Pinheiro, J. Q. (1997). Psicologia Ambiental: a busca de um ambiente melhor. Estudos de Psicologia, 2, 329-333.

Pinheiro, J. Q. (2002). Apego ao futuro: escala temporal e sustentabilidade em Psicologia Ambiental. Em V. Corra-Verdugo (Org.), Conductas protectoras del ambiente: teoria, investigación y estratégias de intervención (pp. 29-48). México: CONACYT/ $\mathrm{Rm} /$ UniSon.

Pol, E. (1993). Environmental Psychology in Europe: from Architectural Psychology to Green Psychology. Aldershot: Avebury.

Ribeiro E. M., \& Galizoni F. L. (2003). Água, população rural e políticas de gestão: o caso do vale do Jetinhonha, Minas Gerais. Ambiente \& Sociedade, 5, 129-146.
Stern, P. C. (2000). Psychology and the science of humanenvironment interactions. American Psychologist, 55, 523-530.

Trigueiro, A. (2005). Mundo sustentável: abrindo espaço na midia para um planeta em transformação. São Paulo: Globo.

Vargas, M. C., \& Paula, G. O. (2002). Água e cidadania: percepção social dos problemas de quantidade, qualidade e custo dos recursos hídricos em duas bacias hidrográficas do interior paulista. Retirado em 01/10/2005, de http://www.anppas.org.br.

Vargas, M. C., \& Paula, G. O. (2003). Introdução na percepção social da água: estudos de caso no interior paulista. Em R. C. Martins $\&$ N. F. L da S. Valencio (Orgs.), Uso e gestão de recursos hídricos no Brasil, Vol. II - Desafios teóricos e político-institucionais (pp. 127-147). São Carlos: RiMa.
Recebido em 28.12.07

Primeira decisão editorial em 23.10.08

Versão final em 17.02.09

Aceito em 05.03.09 